CASE REPORT

\title{
What the Oncologist Needs to Know about Axillary Web Syndrome
}

\author{
Ray CMayo* \\ MD Anderson Cancer Center, The University of Texas, USA
}

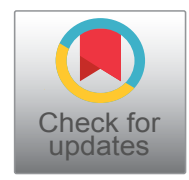

*Corresponding author: Ray Cody Mayo, MD, Assistant Professor, Department of Diagnostic Radiology, MD Anderson Cancer Center, The University of Texas, 1515 Holcombe Blvd, Unit 1350, Houston, TX 77030, USA, Tel: 713-745-4555, Fax: 713-563-9779, E-mail: RCMayo@mdanderson.org

\section{Keywords \\ Axillary web syndrome, Cording, Breast, Postoperative}

\section{Case Report}

A 60 yr female underwent bilateral skin sparing mastectomy with bilateral sentinel lymph node biopsies. Two months after her surgery, the patient began to notice increasing constant "pain and stiffness" in her shoulders bilaterally and difficulty "reaching overhead". Upon presentation to her health care team, she was noted to have impaired shoulder range of motion bilaterally related to bilateral thick axillary cords. The symptoms had slowly progressed since surgery and she had found nothing to provide relief. Shortly thereafter she began to notice worsening edema in the bilateral upper extremities and was referred to physical therapy. Over the next month, with several PT sessions weekly, her range of motion improved significantly, but her edema persisted. After several sessions of therapy she began to notice small palpable lumps in the axilla bilaterally and in her right proximal forearm. Ultrasound of the axilla showed multiple small cystic masses correlating with the palpable areas (Figure 1). She also was found to have cystic masses in her right forearm identical to those found in her axilla (Figure 2). These masses were avascular and completely compressible. All these cystic masses presumably represent the same process: Dilated lymphatics and superficial vessels found in the cords.

\section{Discussion}

Axillary web syndrome (AWS) may present in the early postoperative period after of sentinel lymph node

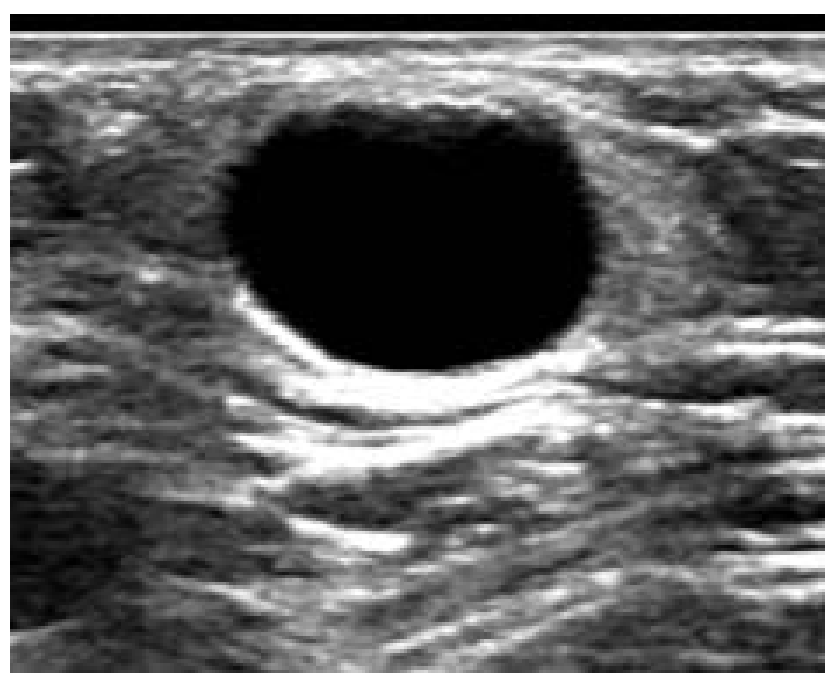

Figure 1: US image of the axillary finding shows a cystic lesion that was completely compressible with manual transducer pressure.

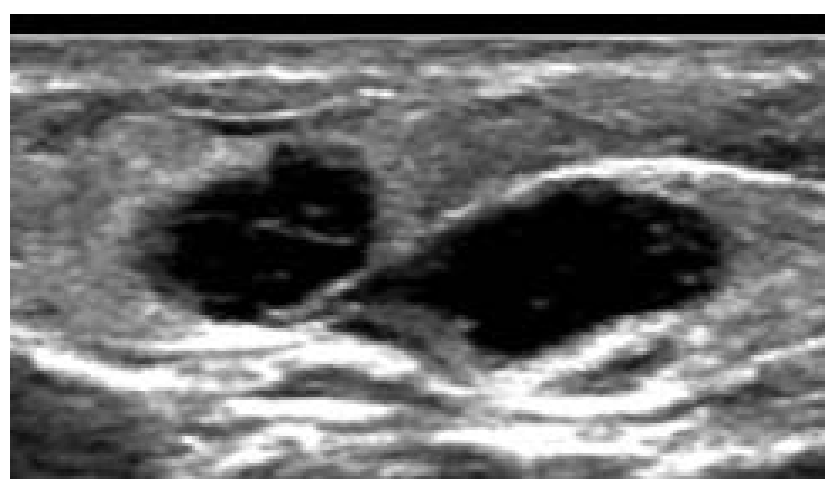

Figure 2: US image of the ipsilateral arm shows similar cystic lesions that were also compressible with transducer pressure. cer Clin Res 5:095. doi.org/10.23937/2378-3419/1410095 
biopsy or axillary lymph node dissection. Local inflammation from lumpectomy or mastectomy sites may also cause AWS [1-3]. Also known as "cording", it presents as a single or multiple "cords" of tissue under the skin that become palpable, painful, and may limit range of motion with shoulder abduction [1-4].

It is important that all oncologist become familiar with this condition since patients may present with symptoms or signs of AWS after surgery. The clinical incidence is estimated at approximately $32 \%$ of cases, ranging from $20 \%$ after sentinel lymph node biopsy and $72 \%$ after axillary lymph node dissection [1,5]. Many radiologists may not be familiar with the condition because there are no studies which have shown that medical imaging can demonstrate the origin or presence of the AWS cords. In fact it has been shown that ultrasound reveals no structure or abnormality that can indicate the diagnosis of AWS [6]. However, ultrasound may still play an important role in the care of these patients by excluding other pathology.

This condition is diagnosed clinically with physical exam revealing a web of palpable, cord like structures typically occurring several days to several weeks after surgery although it may present later [1-2,7,8]. In some cases the cords are not palpable, but the patient will endorse symptoms of pain and tightness while raising the arm [9]. The cords usually start at the surgical site in the axilla and may extend down the medial arm to the antecubital fossa and even into the hand. Some cases may present with cording extending down the chest wall into the abdomen wall $[2,7,10]$.

The etiology of AWS is not completely understood. Most experts believe it may be caused by temporary changes in local vascular or lymphatic systems. Several studies of dissected cords have shown thrombosed and dilated lymphatics and superficial veins. For this reason AWS may be considered a variant of Mondor's disease, which is a superficial thrombophlebitis presenting with a palpable cord on the breast $[2,11,12]$.

AWS can be especially problematic if it happens before or during radiation therapy since the patient is required to lift the arm above the head. AWS usually resolves spontaneously within 3 months and therapy has been shown to be minimally effective $[3,7,8]$. Patients may perform exercises that gently stretch the cords and improve range of motion. Patients may also be referred to therapist who using different myofascial release techniques. An audible pop may be head if a cord breaks during stretching.

\section{References}

1. Leidenius $M$, Leppänen $E$, Krogerus $L$, von Smitten $K$ (2003) Motion restriction and axillary web syndrome after sentinel node biopsy and axillary clearance in breast cancer. Am J Surg 185: 127-130.

2. Moskovitz AH, Anderson BO, Yeung RS, Byrd DR, Lawton TJ, et al. (2001) Axillary web syndrome after axillary dissection. Am J Surg 181: 434-439.

3. Josenhans E (2007) Physiotherapeutic treatment for axillary cord formation following breast cancer surgery. Pt Zeitschriftfür Physiotherapeuten 59: 868-878.

4. Koehler LA (2006) Axillary web syndrome and lymphedema, a new perspective. Lymph Link 18: 9-10.

5. Jean O'Toole, Cynthia L Miller, Michelle C Specht, Melissa N Skolny, Lauren S Jammallo, et al. (2013) Cording Following Treatment for Breast Cancer. Breast Cancer Res Treat 140: 105-111.

6. Koehler LA, Hunter DW, Haddad TC, Blaes AH, Hirsch AT, et al. (2014) Characterizing Axillary Web Syndrome: Ultrasonographic Efficacy. Lymphology 47: 156-163.

7. Leduc $O$, Sichere M, Moreau A, Rigolet J, Tinlot A, et al. (2009) Axillary web syndrome: nature and localization. Lymphology 42: 176-181.

8. Torres Lacomba M, Mayoral Del Moral O, Coperias Zazo JL, Yuste Sánchez MJ, Ferrandez JC, et al. (2009) Axillary web syndrome after axillary dissection in breast cancer: a prospectivestudy. Breast Cancer Res Treat 117: 625-630.

9. Lauridsen MC, Christiansen P, Hessov I (2005) The effect of physiotherapy on shoulder function in patients surgically treated for breast cancer: A randomized study. Acta Oncol 44: 449-457.

10. Bergmann A, Mendes VV, de Almeida Dias R, do Amaral E Silva B, da Costa Leite Ferreira MG, et al. (2011) Incidence and risk factors for axillary web syndrome after breast cancer surgery. Breast Cancer Res Treat 131: 987-992.

11. Rashtak S, Gamble GL, Gibson LE, Pittelkow MR (2012) From furuncle to axillary web syndrome:shedding light on histopathology and pathogenesis. Dermatology 224: 110-114.

12. Alvarez-Garrido $H$, Garrido-Ríos AA, Sanz-Muñoz C, Miranda-Romero A (2009) Mondor's disease. Clin Exp Dermatol 34: 753-756. 